\title{
Os policiais podem ser controlados?
}

ANTONIO OLIVEIRA"

\section{Resumo}

A atividade policial na democracia impõe a questão sobre o controle dos policiais, ou seja, como assegurar que eles, em sua tarefa de assegurar a ordem pública, não violarão os direitos dos cidadãos. A organização policial inclina-se em direção aos mecanismos formais de controle como as normas e os procedimentos, mas essas formas de regulação de conduta podem ser insuficientes, devido à ampla margem de liberdade que os guardas desfrutam nas ruas. Tomando-se como referência os discursos de oficiais policiais militares da Bahia, este artigo discute a prática policial na sociedade democrática e a percepção elaborada pelos policiais dos mecanismos de controle de seus pares e conclui enfatizando os obstáculos que podem ser encontrados na tarefa de controle dos policiais, empecilhos cuja superação torna-se difícil porque têm origem na própria atividade policial.

Palavras-chave: Polícia. Policiamento. Democracia. Cidadania. Estado de Direito.

\footnotetext{
* Professor da UFBA e Doutor em Ciência Política pela USP.
} 


\section{Introdução}

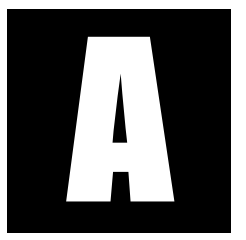

atividade policial na sociedade democrática impõe a questão do controle dos agentes policiais, ou seja, como assegurar que os detentores imediatos da força pública não violarão os direitos civis. Alguns dos meios institucionalizados para garantir essa regulação são os mecanismos instituídos pela própria organização: os controles internos. A organização policial inclina-se em direção aos mecanismos formais de controle, como as normas e os procedimentos, mas esses modos de regulação de conduta podem ser insuficientes, devido à ampla margem de liberdade que os guardas desfrutam nas ruas, autonomia que deriva, em larga medida, da própria natureza da tarefa de policiamento. Este artigo discute os mecanismos de controle do policiamento na sociedade democrática com o objetivo de apresentar argumentos sobre os obstáculos impostos à regulação da conduta dos policiais nas esquinas da cidade, argumentos derivados de reflexões teóricas e de dados produzidos pela pesquisa para a tese de doutorado em que foram entrevistados em profundidade 41 oficiais policiais militares de todos os postos. O texto está dividido em quatro seções. Na primeira e na segunda, analisa-se o debate acadêmico sobre a regulação dessa atividade, a fim de assinalar-se que as dificuldades impostas a essa regulação não podem ser reduzidas a questões locais e conjunturais, pois elas têm raízes na própria ocupação profissional. Na terceira seção, discutem-se os mecanismos de controle e seus limites e recorrem-se às falas de oficiais da Polícia Militar da Bahia para servirem de referência aos argumentos; e a conclusão enfatiza os empecilhos aos controles externo e interno dos agentes que patrulham as ruas. 


\section{A regulação dos agentes policiais}

A função da força pública ${ }^{1}$ é marcada pela ambivalência, pois a repressão do, e a proteção ao, cidadão decorrem da mesma ação policial. Isso é sublinhado por José Vicente Tavares dos Santos: "o exercício da coerção física legítima e o desempenho de uma função social marcada pelo consenso, isto é, o exercício de funções de bem-estar social ou de relacionamento com as coletividades ou comunidades locais" (TAVARES DOS SANTOS, 1997, p. 161). No entanto, essa ambivalência é algo com que o corpo social tem de conviver, enquanto a violência empregada pelo agente for legítima.

O público em geral e as autoridades políticas demandam ao policial, algumas vezes, práticas abusivas contra os transgressores da lei e os promotores de desordens. A admissão da justiça particular em relações privadas gera pedidos de atos abusivos quando a desordem se instaura, ou ameaça instaurar-se, na esfera pública: "o arbítrio e a violência podem ser a resposta do policial a demandas da população especialmente de baixa renda" (PAIXÃO; BEATO,1997, p. 246). O contexto social em que se inscreve o abuso do policial é mais complicado do que se sugere e a violência desse agente tem, não raras vezes, a conivência da população. Teresa Pires Caldeira (1991) analisou essa cumplicidade quando abordou o desprezo da sociedade brasileira em relação aos direitos civis e humanos. Esta pesquisadora discute um fenômeno mais geral que perpassa o imaginário coletivo no Brasil e que ajuda a compreender o uso excessivo de força da parte de agentes públicos: a representação social do corpo. Para ela, o corpo é concebido pela sociedade brasileira como um espaço onde a inflição de dor e outras formas de intervenção são largamente permitidas:

1 Este artigo trata apenas do policiamento ostensivo nas cidades, que, no Brasil, é tarefa de polícias militares estaduais. 
(...) o corpo incircunscrito é desprotegido por direitos individuais e, na verdade, resulta historicamente da sua ausência. No Brasil, onde o sistema judiciário é publicamente desacreditado, o corpo (e a pessoa) em geral não é protegido por um conjunto de direitos que o circunscreveriam, no sentido de estabelecer barreiras e limites à interferência ou abuso de outros (CALDEIRA, 2000, p. 370).

Se há essa concepção social do corpo e se a ela se junta a complicada questão da avaliação de dado comportamento ser ou não transgressor da lei (BLACK, 1979), torna-se difícil a consolidação de mecanismos que imponham obstáculos à agressão física ilegítima praticada pelos policiais, pois este tipo de coerção empregado contra criminosos e marginalizados pode não ser percebido pela sociedade em geral como abuso de poder, mas como merecido castigo aplicado ao desviante. E, nesses casos, a coletividade não denuncia, nem quer testemunhar contra o guarda que, a seus olhos, agiu corretamente (quanto ao apoio dos cidadãos aos abusos do policial, ver também BRICEÑO-LEÓN et al. 1999). Com estas observações, não se pretende isentar de responsabilidade as autoridades policiais pelas práticas ilegais cometidas por elas próprias e por seus subalternos. Apenas se evidencia a complexidade do cenário onde ocorrem os excessos e a necessidade de criar-se mecanismos institucionais que não thes permitam responder às demandas autoritárias dos cidadãos, ainda que haja dificuldades para a consolidação desses mecanismos.

A discussão do mau uso do poder policial é orientada quase sempre pelo recurso à agressão física. Embora seja a mais dramática e visível forma de excesso, ela não é a mais frequente. Os abusos mais comuns, provavelmente, concentram-se nos encontros de pouca visibilidade entre o agente público e os cidadãos de segunda classe e envolvem vários tipos de coerção ilegal. Além disso, há mais um problema que não é contemplado pela discussão sobre a força ilegítima: a polícia dispõe de uma fonte de suspeitos, ou seja, um conjunto de pessoas que ela põe a sua disposição e a quem ela recorre quando necessita produzir culpados e resolver em 
pouco tempo alguma ocorrência criminal, sobretudo as de grande repercussão social. A polícia utiliza arbitrariamente essas pessoas para a resolução de casos, para apresentar ao público as provas de sua eficiência, e, não raras vezes, essa prática tem a aprovação das autoridades políticas, elas mesmas ciosas de exibirem resultados ao público. Essa produção de uma fonte de suspeitos pela polícia é universal, assim como é universal também o perfil dos eleitos: indivíduos pobres membros de algum grupo marginalizado e os criminosos, ou seja, as pessoas que nos estereótipos vigentes preenchem as características de um bandido e algum infrator conhecido que negocia confissões em troca de favores ou para não ser alvo da violência do policial.

As medidas que podem reduzir o emprego do constrangimento físico nos encontros mais visíveis não implicam inibir nem este tipo de coerção em situações pouco iluminadas nem os outros abusos, como o indicado anteriormente. Pelo fato de serem muito pouco expostos à luz, os excessos praticados na penumbra são objeto de difícil apreensão, dificultando tanto a análise das situações em que eles ocorrem quanto a elaboração de propostas para sua solução. Devido ao fato de as pesquisas empíricas sobre a conduta indevida do guarda nos encontros de pouca visibilidade serem escassas no Brasil, a discussão teórica aqui apresentada permanece restrita ao uso da violência na atividade policial - neste texto, identificada exclusivamente com agressão física - e às dificuldades de seu controle ${ }^{2}$. Talvez, de forma indireta, se exponham os empecilhos à

2 Os dados que servem para argumentar que há uso excessivo de força são os de homicídios, porque são as cifras mais precisas sobre a agressão física. Isto não significa que todos esses assassinatos foram ilegítimos, mas a quantidade deles pode ser evidência da necessidade de melhor qualificação dos profissionais. Na cidade de São Paulo, entre 2001 e 2003, os policiais militares assassinaram 1887 pessoas, o que corresponde a 14\% do total de homicídios dolosos ocorridos no período na capital paulista (os dados para os policiais são da Folha de S. Paulo (03/10/02; 11/02/04), e os dos homicídios em geral, da SENASP). Para a cidade de Salvador, há dados para os anos de 1999 e 2000: os patrulheiros foram responsáveis por 208 mortes, o que correspondeu a 17\% dos homicídios dolosos nessa capital (os dados para os policiais são da Corregedoria da PMBA e os dos homicídios dolosos, da SSP-Ba). 
regulação das truculências e da corrupção em geral, principalmente em encontros pouco visíveis dos cidadãos com os policiais.

É necessário enfatizar que violência e brutalidade não são termos intercambiáveis. A última implica uma série de comportamentos indevidos do guarda (agressão verbal, gestos obscenos, rispidez etc.), enquanto a agressão física é uma entre as várias formas de tratamento impróprio que ele pode dispensar às pessoas. A força excessiva é um risco na ocupação de um profissional que lida com o perigo e é treinado para, e autorizado a, usar a força, inclusive a fatal. A questão que permanece é o quantum de violência é justificável e em quais situações.

As prescrições legais são muito vagas e gerais para servirem de guias precisos aos policiais que, nas ruas, enfrentam situações ambíguas e devem responder a elas de imediato. Por isto, algumas agências de polícia elaboram regras mais claras e restritivas para o uso da força letal na atividade de policiamento, discriminando as situações em que esse tipo de violência não é permitido, porém não há a mesma cautela com relação à força não fatal. A falta de claro padrão para o recurso à agressão física em geral faz com que o agente público dependa de sua discricionariedade para decidir se deve ou não exercer este seu direito em determinado encontro (REISS, 1971). Todavia, não se deve atribuir à negligência das autoridades policiais a falta de prescrições precisas e inequívocas para o uso da violência em geral, sobretudo da força não letal, pois essas providências talvez não possam ser tomadas devido à natureza da ocupação policial: o quantum de força deve usar-se e em que situação. A pergunta parece ser irrespondível, enquanto a situação a ser confrontada pelo agente permanecer em aberto, e a noção de força necessária, vaga. O recurso à coerção física como um meio de resolução de conflitos envolve essa complexa questão estrutural que não será superada com as perplexidades e a genuína revolta da população diante dos excessos dos detentores imediatos da força pública.

Além disso, os policiais frequentemente concebem a si mesmos como a tênue linha que separa a ordem da desordem. Este senso de que 
sua missão é combater a desordem, os grupos perigosos e os desregrados pode dar conta de muitos de seus abusos, pois, no afã de tornar o mundo melhor ou mais limpo, o policial pode enveredar pelo caminho da ilegalidade, desde que este lhe pareça mais eficiente para atingir os fins por ele prescritos (quanto a essa prática na polícia civil, ver KANT DE LIMA, 1995; BRETAS; PONCIONI, 1999). Além desse sentimento de dever para com a boa sociedade, aprende-se, na socialização informal, que os colegas recompensam as ações agressivas e punem o comportamento cauteloso: policiais cautelosos são vistos como parceiros de risco, pois expõem ao perigo o colega (LESTER, 1996). Os agentes da força pública que não confrontam o cidadão quando este os desafia são reprovados pelos seus pares:

Existe forte crença subcultural que o policial, ao ignorar os desafios dos cidadãos, perde o respeito do conjunto da população e torna difícil a outros policiais trabalharem no local. O código policial proíbe "dar as costas" (REISS, 1971, p. 150).

Outro componente da cultura ocupacional que favorece o abuso do poder é o fato de o policial conceber os desafios dos cidadãos como um desacato à sua pessoa (BECKER, 1991), ou seja, ele não percebe sua autoridade como funcional: "o policial pensa a si mesmo não como um instrumento do governo, mas como uma pessoa em interação com outra pessoa" (TOCH, 1996). A personalização da relação entre o profissional e o cidadão pode ter efeito negativo, pois o fato de o guarda dar as costas ao tratamento incivil que lhe foi dispensado pelo cidadão pode ser visto pelos parceiros como aceitação da humilhação, e não como evitação de um confronto que pode desencadear atos violentos de consequências imprevisíveis, e o resultado desse modo de perceber as coisas pode ser o conflito que deveria ter sido evitado pelo policial.

Nesse debate acerca do controle da coerção física no policiamento, costuma-se fazer distinção entre a regulação da força letal e a da não fatal. Ainda que o recurso à força mortal seja tido como de mais fácil controle, 
os estudos revelam que se sabe muito pouco sobre as condições e as situações em que ela é usada (WAEGEL, 1984; GELLER; SCOTT, 1992). Mas, após comparar o uso da força letal entre várias unidades de polícia, Geller e Scott sugerem que este uso está associado à reverência à vida humana nutrida pela cultura organizacional da agência e que os administradores da polícia podem estimular este princípio, através da adoção de uma política clara e consistente de restrição ao uso da força mortal; uma política em que são relevantes o treinamento, o desenvolvimento de táticas e de instrumentos alternativos, a liderança, a política de pessoal e a declaração constante e firme em defesa da vida.

O trabalho de Waegel é dirigido às representações dos policiais quanto ao emprego da violência letal, e o autor sublinha tanto as crenças prospectivas que influenciam sua decisão de usar as armas quanto as interpretações retrospectivas dos eventos ocorridos. As primeiras são valores e princípios defendidos pelo agente e que the permitem violar tanto as proibições gerais quanto as regras específicas da agência policial, fornecendo a justificativa para a conduta indevida; as segundas são interpretações particulares do acontecimento em que o agente se envolveu e revelam os modos específicos de as pessoas justificarem suas ações quando requeridas a fazê-lo (WAEGEL, 1984, p. 145).

Esses mecanismos de justificação da conduta ilegal podem ser denominados de técnicas de neutralização, ou seja, racionalizações que negam a existência da vítima e a da agressão ao olhar a outra pessoa como alguém que merece a injúria aplicada e, por conseguinte, absolvem da pena aquele que inflige o dano:

A própria indignação moral e a dos outros são neutralizadas por uma insistência na afirmação de que a injúria não era errada à luz das circunstâncias e em relação a quem ela foi aplicada, ao contrário, ela era um modo correto de retaliação ou de punição; a injúria não foi de fato uma injúria (SYKES; MATTA,1957, p. 668; tradução livre). 
As pessoas categorizadas por estereótipos são vistas como diferentes em uma forma essencial dos cidadãos respeitáveis. Em alguns casos elas são percebidas como subumanas quando rotuladas de anormais; é imputado a elas a inferioridade moral, o que as torna merecedoras do tratamento abusivo aos olhos tanto de quem aplica a punição quanto, muitas vezes, da sociedade em geral. Essas técnicas de neutralização utilizadas pelos delinquentes são apropriadas para interpretar-se a conduta do policial infrator, uma vez que, ao infringir o código penal, ele se torna um ofensor, e não parece haver razão para interpretar-se o comportamento delinquente do guarda de modo diferente ao que se emprega na compreensão da conduta de outros transgressores. Se, por um lado, os policiais adotam técnicas de neutralização da culpa, por outro lado, eles estão dispostos a reconhecer seus erros em alguns casos em que recorreram à força mortal. Todavia, a maioria deles acredita que os enganos são inevitáveis devido à especial natureza de seu trabalho, principalmente porque eles devem decidir sobre o emprego da arma em frações de segundo ("I'd rather be judged by twelve than carried out by six"; WAEGEL, 1984, p. 147). Eles alegam que seus encontros com o público são invariavelmente complexos e ambíguos, tornando a culpabilidade de qualquer guarda em dada situação difícil de ser avaliada. Desde que os métodos duvidosos sirvam ao propósito de fazer justiça, eles caem dentro da definição do comportamento aceitável pelos profissionais:

A presteza a dispensar justiça nas ruas está enraizada em três crenças amplamente compartilhadas: 1) atirar em suspeitos dispensa uma versão de justiça não comumente dispensada pelas cortes; 2) o público quer que a polícia atire em suspeitos quando eles são vistos cometendo um crime; 3) atirar em suspeitos tem o efeito de dissuasão que beneficia os cidadãos respeitadores da lei (WAEGEL,1984, p. 149). 
Devido à constatação do peso das regras informais na conduta do agente e à natureza do policiamento, que se desenrola frequentemente em condições de pouca visibilidade, os resultados do debate sobre o controle da ação policial talvez não permitam muito otimismo. Alguns pesquisadores inspirados no interacionismo simbólico são céticos quanto à eficácia de qualquer controle externo - inclusive o da hierarquia da polícia -, porque a atividade policial seria orientada basicamente pelas regras informais derivadas da cultura ocupacional e pelas situações do encontro entre o agente público e o cidadão, ou seja, pelo tipo de interação que se dá entre os dois atores no curso do evento, e isso poria em dúvida o controle dos policiais mediante as regras formais. Diversos são os trabalhos que fornecem indícios que confirmam essa reflexão. Contudo, pode apontar-se um problema com esse ceticismo. Quando os especialistas afirmam que os policiais estão sempre preocupados em encontrar cobertura, ou seja, em produzir aparência de legalidade para seus atos, afirma-se, indiretamente, que eles têm de observar as regras formais, pois, caso eles as ignorem todo o tempo, ou delas afastem-se muito, haverá dificuldades para cobrirem-se. Esquece-se também que a cultura profissional não é construída sobre um vazio social, ou seja, a cultura policial incorpora elementos das normas, dos princípios, dos valores e das leis vigentes na sociedade e na corporação em que o agente está inserido.

Na discussão deste tema, ou seja, o do peso da cultura ocupacional na conduta do agente, vale sublinhar a contribuição de Clifford Shearing e Richard Ericson, pois eles frisam que a transmissão da cultura policial não é um processo automático de internalização das regras. Ela se dá através de uma coleção de histórias e de aforismos que instruem os policiais sobre como ver o mundo e agir nele (discutindo a prática policial no Brasil, Roberto Kant de Lima (1989) aponta o uso corriqueiro de histórias através das quais os policiais apresentam as suas concepções sociais). As histórias 
e os aforismos, através de suas múltiplas reticências, reservam o espaço para a interpretação e a criação dos policiais individuais, pois elas proveem os agentes com instrumentos que eles podem empregar em seu trabalho, entretanto sem minimizar o fato de que isto ainda requer sua iniciativa (SHEARING; ERICSON, 1991, p. 489-492). Essa reflexão enfatiza o papel ativo dos agentes e, ao fazê-lo, mostra que o policial individual é o árbitro final ou o mediador das influências estrutural e cultural da ocupação. Isto indica que as pressões ocupacionais são mediadas pelas experiências individuais (CHAN, 1996), e, portanto, que a cultura policial é dependente do ambiente político, social, legal e organizacional no qual ela se desenvolve. A proposição segundo a qual as ações do guarda são bastante afetadas pela cultura ocupacional é verdadeira, mas a de que esta cultura é moldada apenas pela prática de trabalho, não. As ações externas podem influenciar a cultura profissional e, por conseguinte, as práticas dos agentes, por isso outros analistas acreditam que os controles exteriores podem influenciar positivamente a conduta do agente nas ruas, ainda que se reconheça a pertinência dos argumentos dos autores que enfatizam a situação do encontro como principal indutor do comportamento do guarda.

O debate sobre a regulação do poder policial está longe de ser esgotado e os termos em que ele é posto envolvem os meios de controles interno e externo.

\section{A eficiência dos mecanismos de controle}

O controle externo sobre a polícia tem limitações como será visto adiante, mas alguns pesquisadores o considera indispensável. Analisando a agressão policial, Paulo de Mesquita Neto indica a pertinência da regulação exterior, mas sublinha o controle interno, pois este traz embutida a necessidade de profissionalização da agência e de melhoria da formação 
dos guardas, o que poderia repercutir tanto na qualidade dos serviços prestados quanto no controle da violência policial (MESQUITA NETO, 1999). Essa relevância dos controles internos, principalmente a qualificação profissional, é enfatizada pelos pesquisadores norte-americanos. Isto não significa recusar os mecanismos externos de controle, sempre defendidos, mas reconhecer que essas formas são insuficientes diante do grau de discricionariedade do agente da polícia, da fluidez de seu mandato e da dificuldade de demonstrar-se o uso da força excessiva no julgamento civil/penal ou nos vários tipos de revisão de sua conduta, sobretudo quando se trata do emprego da força não letal contra cidadãos marginalizados em encontros pouco visíveis. Por causa dessa complexidade, os mecanismos empregados para o controle do policial tendem a ser múltiplos, como argumenta David Bayley ao apresentar diversos mecanismos de regulação adotados por diferentes países, mas sempre uma combinação de métodos externos e internos (BAYLEY, 1996, p. 286-290; 1998).

A má conduta do policial é difícil de ser demonstrada por várias razões: a ausência de uma teoria da força excessiva que permita identificar sem equívoco o abuso do policial; a suspeição dos denunciantes perante o tribunal; a maior credibilidade do agente público frente ao acusado de crime; a relutância de testemunhos policiais; e a indisposição pública de aplicar aos funcionários da lei as penas reservadas aos delinquentes (KLOCKARS, 1996). Podem acrescentar-se ao rol desses empecilhos, "a identidade de interesses entre a polícia e os promotores e a necessidade de manutenção de boas relações de trabalho (...)" (CHEH, 1996, p. 252). Outro fato que minimiza o efeito das ações judiciais sobre o uso da força excessiva é indicado por Albert Reiss: "Quando ocorre a má conduta policial, a organização não é atingida, por isso ela não precisa temer a má conduta, exceto em casos escandalosos" (REISS, 1992, p. 75). A lei criminal não tem como agir sobre a agência de polícia e sua organização, por- 
tanto as fontes sistêmicas do mau comportamento individual não sofrem perturbações, ou seja, os fatores organizacionais que favorecem a conduta indevida permanecem intocáveis, a exemplo das formas de promoção e da distribuição de prêmios que privilegiam a bravura e o destemor.

Jerome Skolnick e James Fyfe sugerem que a raridade das condenações de policiais em processos criminais advêm do fato de que leigos não são adequados para julgar delitos decorrentes da má conduta ocupacional, pois falta-Ihes a competência técnica necessária para avaliarem se houve prática inadequada:

Não é menos difícil para os jurados em julgamentos criminais concluir, além de qualquer dúvida razoável, que as ações profissionais da polícia foram criminosas ao invés de medidas defensivas apropriadas. Os promotores sabem disto e eles não gostam de perder. Os promotores são relutantes a agir contra a própria polícia, sua parceira usual em procedimentos criminais (SKOLNICK; FYFE, 1993, p. 199).

De fato, é difícil o julgamento da conduta indevida de qualquer profissional na execução de seu trabalho, uma vez que a profissão desfruta o reconhecimento social de que só os expertos sabem como executar determinada tarefa, o que exclui, portanto, o leigo de julgar com competência o modo como o profissional, enquanto especialista, agiu no cumprimento de sua missão, exceto quando há erro óbvio e grosseiro, a exemplo do bisturi que é esquecido dentro do paciente. Nos demais casos, a própria Justiça, para emitir seu juízo, recorre ao parecer técnico dos colegas de quem está sob julgamento. Esses empecilhos à avaliação do mau comportamento do agente de polícia fizeram com que Carl Klockars sugerisse uma teoria da força excessiva; uma teoria que servisse de referência para avaliar se a coerção usada pelo policial em determinado evento foi a necessária e nada além disso. 
Não se pode identificar com exatidão a força excessiva, exceto em casos óbvios e raros. A definição oferecida pela mais alta corte norte-americana de apelo é insuficiente para os pesquisadores dos Estados Unidos (basta citar que um dos itens exigidos por essa corte para caracterizar-se a violência como abusiva é o seu caráter manifestamente sádico). A distinção feita pelos tribunais brasileiros entre força e violência também não é satisfatória por ser vaga demais: a primeira é a força necessária; a segunda, a excessiva. Assim sendo, para Klockars, tornar-se-ia indispensável elaborar a teoria da força excessiva, a fim de que se pudessem adotar medidas reguladoras do uso da agressão física. Para elaborar essa teoria, a polícia deve tomar como referência seus profissionais mais altamente qualificados: "Força excessiva deverá ser definida como o uso de mais força que um policial altamente qualificado consideraria necessário usar naquela situação particular" (KLOCKARS, 1996, p. 8). A partir dessa definição, poder-se-ia avançar na discussão do controle da violência, pois ela engloba tanto os casos de abusos já definidos em leis e regulamentos quanto aqueles de menor visibilidade e os decorrentes da falta qualificação profissional.

Estas observações sobre os mecanismos de controle são judiciosas, pois mostram que a transferência à justiça comum do julgamento dos abusos e crimes de policiais militares no Brasil pode não ter impacto significativo no uso da força ${ }^{3}$, principalmente no da não letal e contra cidadãos de segunda classe, que, uma vez agredidos, não se sentem à vontade em denunciar e, quando denunciam, têm pouca credibilidade perante as

3 Os policiais militares estão sob a legislação civil para os crimes de homicídio desde 1996 e alguns deles continuam assassinando com a mesma desenvoltura do período anterior à lei que transferiu o julgamento de guardas homicidas para o tribunal civil. Quando menos, a Polícia Militar de São Paulo não reduziu suas taxas de assassinato (1996, p. 368; 1997, p. 436; 1998, p. $466 ; 1999$, p. $577 ; 2001$, p. 590; 2002, p. 541; 2003, p. 756). Isto reforça a tese defendida por alguns especialistas de que as decisões do judiciário e a lei criminal não têm muito impacto sobre a violência policial, inclusive sobre o uso da força letal. A média anual de homicídios praticados pelos milicianos paulistas, entre 1990 e 1992, era de 1030; depois do escândalo do Carandiru, a média entre 1993 e 1996 caiu para 388 (Folha de S. Paulo, 27/04/2000), o que indica a importância dos controles internos e, provavelmente, dos informais. 
agências públicas e à própria sociedade. Ademais, como pesquisadores americanos argumentam, as ações judiciais não coíbem o uso excessivo da força não letal:

Nem a prática e a teoria nem a realidade e a percepção coincidem sempre, e a concepção geral da influência das Cortes sobre a atividade policial é exagerada. A exclusionary rule não inibe práticas abusivas (SKOLNICK; FYFE, 1993, p. 94).

Além disso, o controle do crime é, frequentemente, visto pelos juizes como um interesse maior, e, quando a força é percebida como necessária para coibir a infração penal, ela é vista também como legítima, ainda que seja legalmente discutível. Em época de sentimento de insegurança exacerbado e de aumento da criminalidade, os meios heterodoxos de obtenção de provas são tomados como legítimos pelas cortes. Na década de 1980, a Suprema Corte norte-americana sancionou a violação de procedimentos legais na obtenção de provas, a exemplo de permitir que o acusado fosse interrogado sem ter sido avisado de seus direitos, ou então ser interrogado na ausência do advogado (SKOLNICK; FYFE, 1993, capítulo 3). Os juizes não parecem muito dispostos a recusar punição a alguém reconhecidamente culpado por causa do comportamento indevido do policial durante a prisão ou a investigação (KLOCKARS, 1991, p. 426); para uma reflexão mais aprofundada sobre a tensão, dentro do sistema penal, entre o "modelo de controle do crime e o modelo do respeito às regras do direito" (ver PACKER, 1968).

O impacto do judiciário sobre a atividade policial não é muito grande, é o que se pode inferir depois de anos de pesquisa e reflexão em um país de democracia consolidada e de judiciário eficiente, quando menos, mais eficiente que o brasileiro. Estas observações não refutam a legitimidade da pretensão de julgarem-se os milicianos na justiça comum, mesmo porque o método democrático é adotado não por ser o mais eficiente, mas por garantir o tratamento equânime dos cidadãos, o qual é um dos 
pilares da democracia. Além disso, uma chave no desenvolvimento da polícia como profissão foi a mudança de sua identificação como força militar empregada para propósitos de segurança interna, ela passou a ser definida como uma agência especializada e autônoma, distinta do exército, para gerenciar os conflitos internos e passou a ser uma organização vinculada ao sistema legal ordinário, e seus integrantes tornaram-se submetidos à legislação e ao procedimento jurídico que atingem os outros cidadãos. As observações apresentadas sobre os limites da intervenção do judiciário na ação policial apenas pretendem ressaltar a complexidade da violência policial e a de seu controle. Os autores americanos parecem inclinar-se à defesa da qualificação profissional como meio mais eficaz para reduzir o uso excessivo de força, pois estão convencidos de que há correlação entre o recurso às formas ilegais de ação e a incompetência técnica para resolver-se adequadamente o conflito.

Neste debate acerca do controle da atividade policial, não se pode ignorar o hábito corrente entre as autoridades políticas e policiais da emissão do chèque en gris, expressão cunhada por Jean-Paul Brodeur (1991) para nomear a prática da prescrição de ordens muito vagas e gerais que permitem ao emissor isentar-se de culpa em casos de abuso da parte de quem as executou, com o argumento plausível de que não emitiu aquela ordem. Porém, o chèque en gris possibilita ao executante também afirmar que sua conduta estava de acordo com dada interpretação da ordem recebida. Desta forma, todos se isentam de responsabilidade: as autoridades políticas, o comandante/chefe de polícia e os policiais subalternos. Aliás, esta declaração de isenção de culpa é muito comum à polícia. Os agentes desta corporação são notórios defensores da autonomia profissional, todavia nunca aceitaram a responsabilidade que a segue. Sua reivindicação de autonomia é acompanhada da imputação de culpa à sociedade em geral - desajuste familiar; desemprego; falta de educação; 
crise dos valores; permissividade - quando eles fracassam na execução de suas tarefas, inclusive na tarefa de regulação da conduta de seus pares nas ruas. Diante das constantes denúncias de agressão policial veiculadas pela imprensa e dos dados de homicídios praticados pelos agentes da força pública, talvez seja relevante discutirem-se os mecanismos de regulação à luz dos discursos daqueles que, dentro da organização, são os responsáveis pela formação, pela supervisão e pela punição desses agentes: os oficiais.

\section{Os mecanismos elaborados pela PMBA}

Nos anos de 1990, os administradores da PMBA iniciaram um processo de reforma organizacional e operacional, a fim de produzir uma agência mais eficiente e agentes mais civis no trato com os cidadãos. Os dirigentes adotaram como estratégia o policiamento comunitário, que pretende envolver a população na definição das tarefas da Corporação, ao mesmo tempo em que esta se torna mais responsável perante aquela. Como é sabido através das notícias transmitidas pela imprensa, o miliciano é frequentemente acusado de comportamento desrespeitoso dos direitos individuais e de uso excessivo de força. Logo, a forma de regulação da conduta dos agentes adotada pela PMBA é peça fundamental para a implementação de uma força pública que cumpre seu papel constitucional de assegurar os direitos fundamentais, entre eles, o da integridade física das pessoas, que não deve ser ameaçada, sobretudo, pelo Estado. A regulação do trabalho policial esbarra em dificuldades impostas pela natureza desta atividade, porém empecilhos não implicam impossibilidade, quer dizer, o fato de que o guarda usufrui de ampla margem de manobra nas ruas não significa que os regulamentos e as normas organizacionais assim como as políticas de recompensa e de punição adotadas e defendidas pela Administração não interfiram em sua conduta ocupacional. 
Na pesquisa empírica, os oficiais foram interrogados sobre as formas de controle da atividade policial mantidas pela PMBA, sobretudo no que diz respeito às praças, pois são elas que vigiam as esquinas da cidade. Além da supervisão do trabalho pelos superiores hierárquicos, a exemplo das rondas dos oficiais, a Corporação instituiu um mecanismo de revisão interna da conduta: as corregedorias. Cada Companhia tem uma corregedoria e um setor de informações que deve não só verificar as denúncias contra os policiais mas ter a iniciativa de investigar a conduta dos agentes na área de sua atuação. Existe ainda a Corregedoria Geral para onde o cidadão se pode dirigir, caso sinta-se constrangido em denunciar o guarda em seu local de trabalho. Em princípio, esses mecanismos internos de revisão de conduta são adequados para apurarem as denúncias do público e proporem medidas corretivas, pois eles são formas de investigação que envolvem os agentes da própria Instituição, o que facilita os trabalhos de apuração do comportamento denunciado, como comprovam as pesquisas que comparam os resultados obtidos pela revisão interna e pela revisão externa das ações do guarda. Afirmar que as corregedorias são um mecanismo adequado de regulação da conduta não significa dizer que elas têm eficácia concreta no caso da PMBA, apenas se afirma que a experiência tem testemunhado a importância dos mecanismos internos de revisão, sobretudo quando eles são comparados aos externos (PEREZ; MUIR, 1996).

Mas, se essas formas de regulação da atividade policial são necessárias, elas não são suficientes. Para que se possa melhor argumentar, decidimos reproduzir alguns discursos dos agentes sobre outros modos de controle:

Eu acho que o Ministério Público, apesar de ostentar essa bandeira do controle externo da atividade policial, mas ele atua de uma forma tímida. Eu penso que ele teme se comprometer, acho que ele diz assim: que se ele atuar muito próximo da polícia, ele vai se comprometer, ou vai se contaminar, vamos dizer. É uma visão sem nenhuma fundamentação, apenas na base do achismo, mas ele não exerce efetivamente (Cel. B). 
Já que somos uma instituição que lida com a violência, com ficar face-a-face com o perigo o tempo todo, eu acharia que o Estado deveria dotar a polícia, tanto a militar quanto a civil, de um departamento de apoio psicológico que atuasse, por exemplo, quando um policial nosso, ele se envolvesse com confronto que houvesse morte, ou que houvesse aquela tensão, aquela adrenalina toda, aquela carga toda, que ele, ao invés de voltar diretamente pro serviço, que ele fosse ter acompanhamento psicológico, porque têm situações que acabam viciando (Ten. I).

O tenente I indica um problema institucional para regular a ação do agente: a falta de uma assistência especializada ao policial que, por alguma razão, se envolveu em episódios de violência, gratuita ou não. O tenente toca na delicada questão de a violência tornar-se um hábito provocado pela profissão, sobretudo porque o agente pode acreditar que as leis não colaboram com seu trabalho e isto pode induzi-lo à justiça privada. O problema de policiais envolverem-se em atos infracionais e fazerem disso um hábito foi discutido por Gary Marx (1988). O entendimento desse problema não é estranho à Administração da PMBA, pois seu Estatuto prevê o acompanhamento social e psicológico de agentes que se envolveram em problemas mais sérios, como nos casos de homicídios, mas parece que essas medidas não foram atualizadas, como indica a fala do tenente e que foi comprovada pela nossa pesquisa. Há alegação da falta de recursos, mas o problema principal pode ser o da importância conferida pela Administração ao tema, pois a milícia dispõe de um quadro de profissionais especializados - assistentes sociais e psicólogos - que poderiam estabelecer o diagnóstico, indicar a terapia adequada e acompanhar os policiais. Ao argumento de que a retirada dos guardas para serem submetidos a esse acompanhamento provocaria falta de pessoal nas ruas, pode responder-se que, se a retirada deles provocará esvaziamento, há, então, policiais demais envolvidos com práticas de violência, tenha 
sido ela necessária ou não, e, além de esses agentes serem uma ameaça ao público e não uma garantia de segurança, a Corporação deve repensar seu modo de preparação dos guardas, pois, ainda que os atos de violência praticados tenham sido legais, eles podem indicar a incompetência técnica dos agentes, que não saberiam empregar meio alternativo à coerção física na resolução do conflito, sobretudo no que se refere ao uso da força letal. Nesses casos, a requalificação profissional pode ser de mais valia do que a simples punição, ou seja, deve-se sublinhar a responsabilidade da organização pelo comportamento de seus agentes.

No debate público sobre o tema é comum assinalar-se a necessidade de órgãos oficiais que tenham a função de fiscalizar o trabalho policial, ou seja, é a defesa do controle externo. Mas, o coronel B indica a existência de um sério problema quanto a esse controle: o Ministério Público não cumpriria seu dever legal por temer agir muito próximo da polícia, por temer contaminar-se, talvez porque a polícia lida com o lixo da sociedade e, pode complementar-se a fala do coronel $\mathrm{B}$, adota métodos sem os quais o sistema penal teria dificuldades para funcionar, mas que são recursos legal e moralmente dúbios, e, assim sendo, a imagem pública negativa da polícia poderia ser transposta para o Ministério Público. A questão central aqui não é a de o discurso do agente revelar ou não a realidade, e sim que ele encontra eco nas reflexões teóricas. Egon Bittner (2003) com uma análise sociológica apurada - e Casamayor (1973) - com uma interpretação mais filosófica - discutiram o porquê de os juizes relutarem em trabalhar mais próximo da força pública, inclusive para fiscalizá-la: o sistema criminal necessita dos meios pouco ortodoxos empregados, às vezes, pelos policiais na detenção do infrator e na apuração dos fatos (por exemplo, sem a suspeição do guarda, que pode ferir os direitos civis e a dignidade humana, os ofensores só seriam detidos em atos visíveis de flagrante delito, ou seja, muitos delinqüentes que respondem a processos 
ou que estão na cadeia não teriam sido apanhados; sem esquecer os métodos de obtenção de provas e de confissões que servirão de guia aos magistrados em sua apreciação do processo, procedimentos que nem sempre seguem às boas regras do direito mas que esclarecem os fatos). Os juizes sabem disso, reconhecem em silêncio essa necessidade e, exatamente por isso, preferem manter-se distante da polícia, a fim de assegurar a imagem imaculada do judiciário dentro de um sistema que está longe de ser virtuoso. Verdade que as análises desses dois autores referem-se ao judiciário, mas elas podem ser transpostas sem dificuldades para a relação entre a promotoria e a polícia e elas permitem entrever os obstáculos ao controle externo da atividade policial pelas instâncias superiores do sistema criminal.

Outra forma de estimular o bom comportamento na ponta do sistema, isto é, nas ruas, seriam as formas de recompensas para os milicianos mais destacados. Contudo, o trabalho na área operacional não é o mais valorizado pela Administração. A pesquisa revelou que os policiais que atuam na área administrativa, ou fora da Corporação, ganham mais, têm mais prestígio e são promovidos mais rapidamente do que seus pares que asseguram a tranqüilidade nas esquinas da cidade. Se o guarda se destaca pela boa conduta e pela eficiência nas ruas, e, por causa disso, os superiores acham que ele deve ser recompensado, seu único prêmio pode ser o de ir para a administração, ou para algum órgão fora da Instituição, isto é, se algum policial se destaca por ser um bom patrulheiro, a população corre o risco de perdê-lo. Portanto, esse mecanismo de controle - recompensa para induzir à boa conduta - que a Administração poderia dispor para regular os agentes na via pública não é eficiente pela simples razão de ele não existir.

Se os oficiais concebem os mecanismos internos de controle como adequados e defendem alguns externos, existiria, porém, um fator que ditaria o comportamento dos guardas e imporia obstáculos ao controle institucional: 
Cabe à sociedade formar pessoas menos preconceituosas, e isto é muito difícil. A PM recebe homens prontos, que já tão formados. A gente dá formação técnica e tenta melhorar essa pessoa como ser humano, mas se ela não tiver receptiva a isso, nada vai fazer ela mudar (Ten. A).

Aí, a gente pega uma pessoa desta da sociedade, que pensa que a polícia pode tudo, entra no curso de formação, aquela formação, por ser no espaço de tempo pequeno, não dá pra trabalhar este homem, até pra mostrar a realidade dos fatos, das coisas, dos acontecimentos. Então, ele entra na Corporação achando que polícia pode tudo, não é? (TCel. B).

Sem pôr em dúvida que a imagem de uma força pública que pode tudo seja decorrente tanto de uma história de autoritarismo político que sempre caracterizou o país quanto da percepção que vigora na sociedade brasileira, de acordo com a qual os direitos individuais e humanos são privilégios (CALDEIRA, 1991), há, nessas falas, uma tendência de o oficial eximir-se da responsabilidade pela conduta dos subordinados, uma vez que eles não teriam como agir sobre as pessoas que chegam à Instituição com atitudes autoritárias. Além dessa inclinação a isentar-se de responsabilidade - porque as pessoas já chegam adultas -, há a imagem que os oficiais constroem das praças e que pode ter impacto nos mecanismos de regulação que os primeiros estabelecem para os segundos.

A origem social e a qualificação profissional das praças são distintas das dos oficiais. Estes, em geral, pertencem às famílias de renda superior àquelas e, mais importante, são submetidos ao curso de formação profissional reconhecido como de nível superior, o que implica distinção clara entre os dois estamentos no interior da Corporação. Quando interrogados se, além das atitudes concebidas fora da PMBA, a origem social das praças dificultava o seu controle, eles responderam que sim. 
A percepção de que a origem social das praças favorece sua má conduta pode ser inserida na visão amplamente compartilhada pela sociedade que associa pobreza ao crime e à violência. Não cabe aqui discutir a pertinência dessa correlação, mas devem analisar-se suas possíveis conseqüências na regulação da atividade policial. Na medida em que se atribui a conduta indevida dos agentes a fatores externos à Instituição, há a probabilidade de os fatores organizacionais que podem influenciar o mau comportamento - a formação técnica deficiente, as formas de recompensa que não levam em consideração a conduta do agente em seu trato com o público e a excessiva distância entre quem planeja e quem executa o trabalho - serem negligenciados frente aos elementos exteriores que favorecem a atuação inadequada dos atores. Não se duvida de que pessoas de comportamento desviante adentrem a milícia e aproveitem o poder do qual são investidas para praticarem abusos, contudo a questão essencial não é esta, mas, sim, os mecanismos que a Corporação dispõe para não permitir, ou para punir, a má conduta do agente e as formas de ela premiar a boa conduta deles nas ruas, ou seja, o foco do debate acerca da conduta do policial nas ruas deve ser deslocado do indivíduo (a famosa maçã podre no cesto sadio) para a organização, como judiciosamente assinalam Reiss (1992) e Bayley (1996).

Quando interrogados sobre a responsabilidade da organização na conduta desviante dos agentes, os oficiais argumentam que se adotam regulamentos disciplinares rigorosos e adequados. Os modos de regulação defendidos pelos oficiais assentam-se nas regras formais e na fiscalização, o que é compatível com sua visão legalista da profissão e com sua defesa da disciplina e da hierarquia militares como forma de controle. Porém essa concepção dos agentes deve ser mais discutida.

As organizações policiais nutrem a visão legalista do ofício que praticam, mas elas reconhecem a ampla margem de manobra permitida pela 
atividade policial (MONJARDET, 1996), o que põe em dúvida a efetividade das regras e dos procedimentos formais para controlar a conduta do agente que está nas ruas; efetividade suposta pela percepção legalista do trabalho policial, pois, se este restringe-se a aplicar a norma legal, os regulamentos e os procedimentos formais podem dar conta do comportamento dos guardas, para isso é suficiente comparar a ação deles - que, pela concepção legalista, se deveria restringir à execução da lei - com as normas e os procedimentos previstos para aquela atuação, e, caso haja discrepância, podem recorrer-se aos códigos formais para efetuar a devida punição. Não parece que os oficiais da PMBA ignorem esse dilema, isto é, que essa visão legalista se choca com o fato de a atividade policial promover a autonomia dos executores, porque estes lidam com eventos e contextos que os códigos não podem dar conta, ou seja, o trabalho policial não é, nem parece que possa ser, o de simples aplicação da lei. Como os oficiais reconhecem a discricionariedade do policial, há a probabilidade de que a defesa acentuada da disciplina militar e a declaração de que a tarefa policial é a de simples execução do estatuto legal sejam recursos de que eles lançam mão para reduzir sua responsabilidade pela má conduta do subalterno: uma vez que a organização assenta-se em uma disciplina rigorosa e a profissão é apresentada como adstrita à letra da lei, o mau comportamento deve ser atribuído, sobretudo, ao desvio individual, que por sua vez pode ser explicado pela origem social do desviante. As fontes sistêmicas da conduta indevida podem ser negligenciadas em favor da explicação que toma como referência os fatores individuais que promovem o abuso dos atores; e, também, camuflam-se os obstáculos ao controle da ação policial que são inerentes ao ofício.

Mas deve-se discutir um pouco mais a relevância da disciplina e da hierarquia militares na tarefa de controle da atividade policial. 
A necessidade da disciplina militar no trabalho policial não é autoevidente, a suposição desta necessidade está baseada na transposição de uma realidade de trabalho para outra bem diferente. As atividades cotidianas do patrulheiro e do soldado não são comparáveis entre si, exceto em termos gerais de que ambas asseguram a soberania do Estado com o recurso à força. A discricionariedade do policial e a fluidez de seu mandato põem em dúvida a eficácia de um modo de disciplina concebido para profissionais que atuam coletivamente sobre um objeto e em situações mais bem definidos e que são diretamente fiscalizados pelo supervisor, como é o caso dos militares. Claro, não se pode afirmar que essa disciplina seja desnecessária ao trabalho policial (parece que ela é relevante para assegurar o bom comportamento do agente dentro dos quartéis, o que por si só é positivo), apenas se sublinha a pertinência da discussão sobre o modo mais eficiente de garantir a boa conduta do miliciano na via pública, pois a forma até hoje tida como a mais apropriada pode ser decorrente de uma época em que, em várias partes do mundo, a polícia se pretendia apresentar como uma agência que controla seus agentes, adotando o modelo de disciplina do exército, sem interrogar se isso correspondia à realidade da operação policial.

Se a prática profissional dos militares pode ser controlada por esse tipo de disciplina, pode não ser o caso do trabalho policial, que, ao contrário da atividade da armada, se caracteriza pela ação individual e de pouca visibilidade, caracteres estes que favorecem a discricionariedade dos atores. Além do quê, deve-se sublinhar, os principais insumos do poder discricionário do policial são a necessidade de o agente ter de adaptar a ordem normativa às ordens cotidianas e o reconhecimento social de que ele pode negociar com alguns violadores da lei de modo a evitar o uso da coerção física e para promover a paz social, dados estes que não caracterizam a atividade do militar, pois quando este experto sai dos quartéis 
é, em geral, para impor a ordem normativa e não para adequá-la à realidade; e o soldado não dispõe da mesma liberdade do policial no que se refere à negociação com os transgressores da ordem pública. Diante de atividades tão distintas, abre-se a discussão acerca da adequação de um mesmo modo de regulação dos atores que a elas se dedicam. Debate esse que se torna premente perante o fato de, até a presente data, a disciplina e a hierarquia militares não parecerem ser suficientes para assegurar a boa conduta dos policiais nas ruas, a acreditar no número de homicídios por eles praticados e nas constantes denúncias de mau comportamento registradas na imprensa e por organizações de defesa dos direitos humanos.

Mas, apesar do apego à hierarquia militar e da visão legalista dos oficiais, a atividade policial é por eles percebida como dependente da situação, do resultado do face-a-face entre o guarda e o cidadão, o que faz com que a habilidade, a experiência e o discernimento sejam decisivos no policiamento e que, aos olhos deles, esses atributos sejam tão relevantes quanto as leis e os procedimentos formais na ocupação policial. Em suma, os oficiais reconhecem e aceitam a police discretion, por causa da natureza de seu trabalho. Sabe-se, porém, que esse poder provoca abusos. Como ele não pode ser extirpado, pois está inscrito na atividade de policiamento, resta saber como evitar ou reduzir os excessos que a margem de liberdade do guarda nas ruas pode gerar.

As ruas constituem a principal zona de incerteza da organização policial, pois a hierarquia pode fazer muito pouco em relação ao controle imediato dos patrulheiros. Estes, além de desfrutarem ampla margem de autonomia na via pública, porque podem selecionar os eventos que merecem sua atenção e estão longe do supervisor, contam com o reconhecimento dos superiores, ao menos informalmente, de que sua discricionariedade é necessária ao ofício que praticam. Parece ser devido, sobretudo, à natureza da atividade de policiamento que os oficiais apostam 
na qualificação profissional como meio mais adequado de regular a conduta dos agentes, pois a qualificação permitiria ao policial atuar de modo mais condizente com as regras e os procedimentos formais impostos pela organização, o que reduziria os desvios. Mas a formação profissional não parece ser também suficiente para os oficiais, e isto é evidenciado quando eles são interrogados sobre o mecanismo que eles particularmente concebem como mais eficiente para assegurar o bom comportamento dos policiais na via pública. Mais uma vez, cabe reproduzir parcialmente algumas falas:

Nós já pensamos em controle eletrônico. No radiopatrulhamento existem estudos de controle através de satélite, mas o homem à pé é complexo. O policiamento ostensivo à pé, ele se tornou difícil de ser fiscalizado, então, eu vou pela questão da conscientização (Maj. E).

Olha, eu me reporto na educação, na conscientização. Eu acho que todo caminho se traduz na educação. Por que na educação? Porque você mostra ao policial a importância dele, conscientiza ele da necessidade dele fazer um bom policiamento (Cap. F).

É preciso ele ter respeito, ele saber: 'olhe, esse pedaço aqui, se eu sair e tiver um assalto, a responsabilidade não é só minha, eu vou trazer um problema pra Corporação, eu sou parte deste processo, o sucesso da Corporação depende de mim, eu tenho responsabilidade' (TCel. E).

Pode ver-se que, ao fim e ao cabo, apela-se à consciência de um profissional que os oficiais sabem que atua isolado e não pode ser acompanhado de perto pelo fiscal - então, como confiar na disciplina militar, que supõe a supervisão direta e imediata dos atores em ação? -, e que se defronta com situações complexas que os regulamentos e os procedimentos não dão, nem podem dar, conta - então, como apostar na visão que sustenta ser o trabalho policial o de simples aplicação da lei? Como 
os oficiais são policiais, eles sabem que não podem jogar todas as suas fichas nem na disciplina militar nem nas regras formais como meios de garantir a boa conduta do guarda nas esquinas, por isso há o recurso a sua consciência. Não se trata de uma particularidade da PMBA, pois o apelo à virtude dos agentes que patrulham as ruas é o recurso último dos que administram o aparelho policial, como pode ver-se no comentário de Dominique Monjardet (1996, p. 283-289).

O apelo à consciência profissional é um recurso de todos os administradores, mas ele tem particular importância quando a função que o agente desempenha não é, nem parece que possa ser, claramente definida, como é o caso do mandato policial, o qual se refere à manutenção da ordem pública, algo por demais vago e fluído; quando a execução do mister é muito dependente das circunstâncias que a envolvem e, por causa disso, não pode ser prescrita com detalhes, ao contrário do que acontece com outros ofícios cujas tarefas têm conteúdos previamente especificados com clareza, o que permite estabelecer com precisão a forma de elas serem efetivadas, forma que independe da ideologia do executor e que é orientada por uma teoria; quando se fica à mercê da iniciativa do agente, porque ele pode selecionar os eventos que merecem sua atenção; quando o executor está longe do olhar do supervisor; quando o processo pelo qual se executa o trabalho é mais importante do que o produto gerado; quando há o problema da revisão do trabalho efetivado: um produto mal feito ou uma prestação de serviço mal conduzida podem ser corrigidos, a ação do policial que altera a vida cotidiana, e até mesmo o destino, dos cidadãos, é muito mais difícil de ser revisada, o patrulheiro pode ser punido, mas isso não anula nem atenua o dano por ele provocado; e, sobretudo, quando os princípios e os valores individuais e de grupo jogam papel decisivo na execução do ofício, pois os policiais lidam com assuntos de ordem moral que causam a reprovação e a repugnância social 
ou que dizem respeito à ajuda a pessoas em dificuldades, e a resolução dessas questões envolve a apreciação subjetiva orientada pelos valores morais dos que as devem resolver, e não há meio de evitar isso. O conjunto dessas situações assinala o trabalho policial, por isso o apelo à virtude do agente torna-se tão essencial, e a questão de sua regulação, tão complexa.

\section{Conclusão}

Os mecanismos de controle externo da atividade policial são uma necessidade óbvia, contudo não se devem ignorar nem a natureza dessa atividade nem que se está diante de uma profissão. Negligenciar a natureza do trabalho policial pode servir apenas para produzirem-se mecanismos de regulação inócuos, como a proposta de unificação das polícias militar e civil, pois não se vê como tal medida reduziria a ampla margem de manobra que os guardas desfrutam nas esquinas da cidade e como uma organização mais complexa e, portanto, mais opaca teria mais controle sobre seus agentes. Por outro lado, os atores externos que pretendem intervir na corporação policial não se devem comportar como se ela fosse um mero instrumento que pudesse ser reformado a qualquer momento e em qualquer direção, bastando para isto apelar ao chamado interesse público. Eles devem lembrar-se que estão lidando com uma profissão, que tem interesses privados, e que, por causa disso, o aparelho escapa a seu controle, no sentido de que as reformas que eles pretendem impor à instituição poderão encontrar resistências internas que dificilmente serão vencidas. A insistência em não reconhecer que o aparelho policial tem autonomia porque é movimentado por uma profissão, e que isto não pode ser eliminado, só pode induzir à negação ou à camuflagem dos problemas inerentes à atividade policial. 
Quanto à regulação interna das ações do miliciano, há a inclinação para a responsabilização individual. Embora isso possa ser imputado à tentativa de o superior livrar-se da responsabilidade pela conduta do subalterno, tal imputação deve ser matizada. A atividade policial personaliza a relação entre o agente e o público, personalização que não é decorrente de uma apropriação indébita da função pública como sugere Hans Toch (1996), ou não o é exclusivamente, mas do fato tanto de o miliciano ser o agente do poder público que é chamado a intervir nas relações privadas e na vida íntima das pessoas quanto de, em sua tomada de decisão, ele levar em conta os indivíduos com seus dramas e com suas circunstâncias concretas (MUIR, 1977), sem que nenhuma teoria ou prescrição organizacional possa orientá-lo. Este estado de coisas produz a personalização da relação entre o policial e o cidadão - isso, sem dúvida, gera efeitos negativos, pois afeta a imparcialidade dos agentes públicos, mas, como decorre da natureza da atividade, não parece que possa ser eliminado; se é que seria desejável tal coisa, pois esta eliminação implicaria que os policiais não deveriam levar em conta a dimensão humana nos eventos em que eles intervêm -, o que, aos olhos do guarda, torna a atividade muito dependente do indivíduo que a executa, ou seja, de seu equilíbrio, de sua astúcia, de sua formação moral, de seu temperamento e de suas atitudes, por causa disso, no universo policial, privilegia-se a responsabilização individual, porém, embora seja compreensível essa concepção que os agentes elaboram a partir de sua situação de trabalho, isto pode desviar a atenção das fontes sistêmicas da conduta incivil, isto é, isentar de responsabilidade a organização pelos profissionais que forma e supervisiona. 


\section{Is it possible to control police officers?}

\section{Abstract}

In a democracy, police activity requires control of the police officers, to make sure that in their task of ensuring public order they will not violate the citizens' rights. The police organization leans toward the formal mechanisms of control, such as rules and procedures, but these forms of conduct regulation may be insufficient, due to the large margin of freedom the officers have on the streets. Examining the discourse of military police officers from the state of Bahia, this article discusses the police practice in a democratic society, and the officers' perception of the mechanisms used to control their colleagues. In the conclusion, the paper emphasizes the obstacles that can be found in the task of controlling police officers, obstacles that are difficult to overcome because they have their origin in the police activity.

Keywords: Police. Policing. Democracy. Citizenship. Rule of law.

\section{Referências}

BECKER, Howard. Outsiders - studies in the sociology of deviance. New York: Free Press, 1991.

BAYLEY, David H. Police brutality abroad. In: GELLER, William A.; TOCH, Hans(ed.). Police violence - understanding and controlling police abuse of force. New Haven: Yale University Press, 1996. p. 273-291. Foundation, 1998.

. Policing in America: assessment and prospects. Washington: Police

BITTNER, Egon. Aspectos do trabalho policial. São Paulo: Edusp, 2003.

BLACK, Donald. Common sense in the sociology of law. American Sociological Review. n. 44, 1979. p. 18-27.

BRETAS, Marcos Luís; PONCIONI, Paula. A cultura policial e o policial civil carioca. In: PANDOLFI, Dulce Chaves et al.(org.). Cidadania, justiça e violência. Rio Janeiro: Editora Getúlio Vargas, 1999. p. 149-163.

BRINCEÑO-LEÓN, Roberto; CARNEIRO, Leandro Piquet; CRUZ, José Miguel. O apoio dos cidadãos à ação extrajudicial da polícia no Brasil, em El Salvador e na 
Venezuela. In: PANDOLFI, Dulce Chaves et al.(org.). Cidadania, justiça e violência. Rio Janeiro: Editora Getúlio Vargas, 1999, p.117-127.

BRODEUR, Jean-Paul. La police - mythes et realités. Les cahiers de la sécurité intérieure. Paris, 6, 1991. p. 310-337.

CALDEIRA, Teresa P. R. Direitos humanos ou 'privilégios de bandidos'?. Novos Estudos Cebrap. São Paulo, n.30,1991. p. 162-174.

. Cidades de muros-crime, segregação e cidadania em São Paulo. São Paulo: Edusp, 2000.

CASAMAYOR. La police. Paris: Gallimard, 1973.

CHAN, Janet. Changing police culture. British Journal of Criminology, v. 36, n. 1, 1996. p. 109-134.

CHEH, Mary M. Are lawsuits an answer to police brutality? In: GELLER, William A.; $\mathrm{TOCH}$, Hans (ed.). Police violence - understanding and controlling police abuse of force. New Haven: Yale University Press, 1996. p. 247-272.

GELLER, William A.; SCOTT, Michael S. Deadly force - what we know. Washington: PERF, 1992.

KANT DE LIMA, Roberto. Cultura jurídica e práticas policiais: a tradição inquisitorial. Revista Brasileira de Ciências Sociais, v. 10, n.4, 1989. p. 65-84.

. A polícia da cidade do Rio de Janeiro: seus dilemas e paradoxos. Rio de Janeiro: Editora Forense, 1995.

KLOCKARS, Carl B. The dirty Harry problem. In: KLOCKARS, Carl B.; MASTROFSKI, Stephen D.(ed.). Thinking about the police. Massachusets: McGraw Hill, 1991. p. 413-423.

. A theory of excessive force and its control. In: GELLER, William A. and $\overline{\mathrm{TOCH}}$, Hans(ed.). Police violence - understanding and controlling police abuse of force. New Haven: Yale University Press, 1999. p. 1-22.

LESTER, David. Officer attitudes toward police use of force. In: GELLER, William A.; TOCH, Hans(ed.). Police violence - understanding and controlling police abuse of force. New Haven: Yale University Press, 1996. p.180-190.

MARX, Gary T. Undercover - police surveillance in America. Los Angels:University of California Press, 1988.

MESQUITA NETO, Paulo de. Violência policial no Brasil: abordagens teóricas e práticas de controle. In: PANDOLFI, Dulce Chaves et al.(org.). Cidadania, justiça e violência. Rio Janeiro: Editora Getúlio Vargas, 1999, p.129-148. 
MONJARDET, Dominique. Ce que fait la police - la sociologie de la force publique. Paris: La Decouverte, 1996.

MUIR, William Ker. Police - streetcorner politicians. Chicago: The University of Chicago Press, 1977.

PACKER, Herbert L. The limits of the criminal sanction. Stanford University Press: California, 1968.

PAIXÃO, Antônio Luiz; BEATO, Cláudio C. Crimes, vítimas e policiais. Tempo Social. USP, v.9, n. 1, 1997. p. 233-248.

PEREZ, Douglas W. and MUIR, William Ker. Administrative review of alleged police brutality. In: GELLER, William A.; TOCH, Hans (ed.). Police violence - understanding and controlling police abuse of force. New Haven: Yale University Press, 1996, p. 213-233.

REISS, Albert J. The police and the public. New Halen: Yale University Press, 1971.

. Police organization in the twentieth century. In: TONRY, M. and MOR$\overline{\mathrm{RIS}, \mathrm{N}}$. (ed). Modern Policing. Chicago: The University of Chicago Press, 1992, p. 51-97.

SHEARING, Clifford; ERICSON, Richard. Culture as figurative action. British Journal of Sociology, 42, 1991. p. 481-506.

SKOLNICK, Jerome H.; FYFE, James J. Above the law - police and the excessive use of force. New York: Free Press, 1993.

SYKES, Gresham and MATZA, David. Techniques of neutralization: a theory of delinquency. American Sociological Review, v. 22, n. 6, 1957. p. 664-670.

TAVARES DOS SANTOS, José Vicente. A arma e a flor - formação da organização policial, consenso e violência. Tempo Social, USP, v. 9, n. 1, 1997. p. 155-167.

$\mathrm{TOCH}$, Hans. The violence-prone police officer. In: GELLER, William A. and $\mathrm{TOCH}$, Hans (ed.). Police violence - understanding and controlling police abuse of force. New Haven: Yale University Press, 1996, p. 94-112.

WAEGEL, William B. How police justify the use of deadly force. Social Problems, v. 32, n. 2, 984. p. 4-155.

Recebido: $17 / 12 / 2007$

Aceite final: 26/08/2008 